\title{
Rancang Bangun Sistem Informasi Laporan Penjualan Heart Snack Pada PT.Flavors International
}

\author{
Muhamad Yusup ${ }^{1}$, Meri Mayang Sari ${ }^{2}$, Andri Saepudin ${ }^{3}$ \\ 1,2,3Program Studi Sistem Informasi Universitas Raharja \\ Email : ${ }^{1}$ yusup@ raharja.info, *22meri.mayang@ raharja.info, ${ }^{3}$ andri.saepudin@ raharja.info
}

\begin{abstract}
Abstrak
Dalam pengolahan laporan penjualan kue pada PT Flavors Internasional masih menggunakan sistem manual sehingga petugas terkait mengalami beberapa kendala dalam pembuatan laporan penjualan. Maka perlu suatu sistem yang dapat menangani kesalahan dalam pembuatan laporan penjualan kue tersebut yang saat ini masih menggunakan sistem manual. Dalam penelitian ini menggunakan beberapa metode yang digunakan meliputi pengumpulan data yang didalamnya terdapat observasi, wawancara, dan studi pustaka, metode SDLC sebagai metode analisis yang digunakan, UML digunakan sebagai tools dalam merancang sistem dalam bentuk usecase, activity, seqeuence, maupun class diagram. Dengan adanya sistem ini permasalahan yang ada dalam proses pembuatan laporan penjualan kue dapat teratasi dengan baik serta dapat memberikan efisiensi waktu dan proses bagi perusahaan, serta pengolahan laporan data lebih teratur.
\end{abstract}

Kata Kunci : Sistem Informasi, Penjualan, Laporan Penjualan.

\begin{abstract}
In processing the cake sales report at PT Flavors Internasional still uses a manual system so that the related officers experience some problems in making sales reports. So we need a system that can handle errors in making the cake sales report which is currently still using a manual system. In this study, several methods are used including data collection which includes observation, interviews, and literature studies, the SDLC method as the analytical method used, UML is used as a tool in designing systems in the form of usecase, activity, seqeuence, and class diagrams. With this system, problems that exist in the process of making cake sales reports can be resolved properly and can provide time and process efficiency for the company, as well as more regular data report processing.
\end{abstract}

Keywords: Information Systems, Sales, Sales Reports

\section{PENDAHULUAN}

Pembuatan laporan perusahaan merupakan faktor penting dalam sebuah perusahaan. Sebagai informasi yang mendalam dan detail mengenai data laporan perusahaan. Penggunaan komputer di bidang pelaporan dapat memberikan manfaat yang sangat besar, baik dalam keakuratan data maupun dalam frekuensi pekerjaan yang ditangani, sehingga penyajian laporan yang dibutuhkan dapat diperoleh dengan cepat, tepat dan lengkap. Proses dalam pembuatan laporan penjualan kue di PT. Flavours International masih melakukan pencatatan secara manual, sehingga keakuratan data dan informasi dalam laporan tidak terjamin dan harus dicek berulang kali serta pencarian datanya tidak cepat, lambat dalam memberikan informasi laporan kepada pimpinan, lambat dalam proses pelaporan dan banyak kesalahan dalam pelaporan. Setiap 
perusahaan bisnis membutuhkan laporan karena merupakan salah satu alat untuk melakukan perencanaan, pengorganisasian, pemindahan, pengendalian, pemantauan dan pengambilan keputusan strategis. Selain itu, laporan merupakan media komunikasi yang efektif untuk menjelaskan kinerja individu, tim, dan / atau perusahaan kepada pihak lain yang membutuhkan baik internal maupun eksternal.[1] Untuk mengatasi masalah tersebut maka peneliti ingin merancang sebuah sistem yang mempermudah kinerja karyawan untuk melakukan proses pelaporan penjualan kue, serta memberikan efisiensi waktu dalam pengolahan data laporan.

\section{Landasan Teori}

Penjelasan mengenai informasi yang dijelaskan oleh Prehanto (2020:12)[2], Hasil pengolahan data dengan cara tertentu sehingga lebih bermakna dan bermanfaat bagi penerimanya, dimana informasi dapat dikatakan bernilai jika informasi tersebut dapat mengambil keputusan yang baik.

Penjelasan mengenai laporan penjualan yang dijelaskan oleh Mahmudi (2018:241)[3], kumpulan informasi penjualan yang disajikan sebagai bahan pencatatan dan analisis penjualan yang berperan penting dalam pengambilan keputusan berupa metode pemasaran, penetapan harga, dan penjualan.

Penjelasan web dijelaskan oleh kristiadi dan ferry (2021: 32)[4], kumpulan halaman berisi informasi yang dapat diambil melalui media internet berupa teks, gambar, suara, video yang memiliki alamat di browser

Penjelasan sistem dijelaskan oleh (2021:11)[5], setiap kesatuan secara konseptual atau fisik yang terdiri dari bagian-bagian yang bergantung satu sama lainnya.

\section{LITERATURE REVIEW}

Bagian ini akan menjelaskan secara detail mengenai keterkaitan dengan penelitian ini

1. Ishak, dkk tahun 2018 dengan judul Rancang Bangun Sistem Informasi Penjualan Kue Dan Roti Berbasis Web Pada Yuki Bakery Jakarta. Dalam peneiltian ini mempunyai tujuan mengenai cara penyampaian suatu informasi serta cara bagaimana memasarkan produk melalui media internet. Meenggunakan penerapan e-commerce ini sangat bermanfaat dalam menangani transaksi yang dilakukan secara online bagi konsumen dan hasil laporan penjualan yang dibuat menjadi lebih spesifik, akurat, dan tepat waktu dalam penanganannya.[6]

2. Nurhayati tahun 2017 dengan judul Implementasi E-Commerce Dalam Meningkatkan Penjualan Kue Di Toko Kemuning. Dalam penelitian ini mempunyai tujuan dalam mengelola transaksi penjualan secara elektronik dengen penerapan e-commerce untuk mengetahui kebutuhan apa saja yang dibutuhkan setiap pengguna agar mampu menignkatkan penjualan produk.[7]

3. Sintawati tahun 2018 dengan judul Pembuatan Sistem Informasi Penjualan Kue Berbasis Web Dengan Metode RAD (Rapid Application Development). Dalam penelitian ini mempunyai tujuan untuk membantu proses operasi produksi, memberikan daya tarik untuk bagian promosi dan proses transaksi menjadi lebih baik, serta memudahkan dalam membuat laporan penjualan dan informasi pendapatan lebih akurat dan detai.[8]

4. Hendini tahun 2016 dengan judul Permodelan UML Sistem Informasi Monitoring Penjualan Dan Stok Barang (Studi Kasus: Distro Zhezha Pontianak). Dalam penelitian ini mempunyai tujuan memudahkan pihak pengelola dalam memantau laporan penjualan dan stok barang yang ada dikantor cabang serta membantu dalam pengambilan keputusan untuk masing-masing kantor cabang.[9] 


\section{METODE PENELITIAN}

Metode Penelitian dalam penelitian ini terdiri dari beberapa metode, seperti dibawah ini:

\section{Pengumpulan Data}

Dalam mengumpulkan data peneliti melakukan beberapa tahap anatra lain :

a. Observasi

Melakukan observasi langsung dengan mengunjungi tempat penjualan untuk mengetahui secara langsung dan mencatat secara sistematis elemen-elemen yang diteliti serta menganalisa sistem yang sedang berjalan.

b. Wawancara

melakukan wawancara langsung dengan stakeholder tentang sistem yang digunakan di perusahaan. Dengan menanyakan beberapa pertanyaan lisan untuk melengkapi data yang ingin didapatkan. Wawancara dilakukan setiap peneliti membutuhkan data. Hal tersebut dilakukan agar peneliti memperoleh data yang akurat.

c. Studi Pustaka studi pustaka ini dilakukan untuk mendukung hasil observasi dan wawancara yang telah dilakukan. Pengumpulan data dilakukan dengan mencari referensi terkait masalah yang diteliti untuk memperoleh informasi yang dibutuhkan, referensi dapat diperoleh dari buku, internet, dan sumber terpercaya lainnya..

\section{Metode Analisa}

Analisis SDLC (System Development Life Cycle) digunakan dalam metode penelitian ini. Dimana SDLC (System Development Life Cycle) adalah Model konseptual yang digunakan dalam manajemen proyek yang menggambarkan tahapan yang terlibat dalam proyek pengembangan sistem informasi, dari studi kelayakan awal hingga pemeliharaan aplikasi lengkap yang dapat diterapkan pada sistem teknis dan non-teknis.[10]

Empat tahap dasar dalam siklus pengembangan sistem atau SDLC dapat dilihat pada gambar 1.[11]

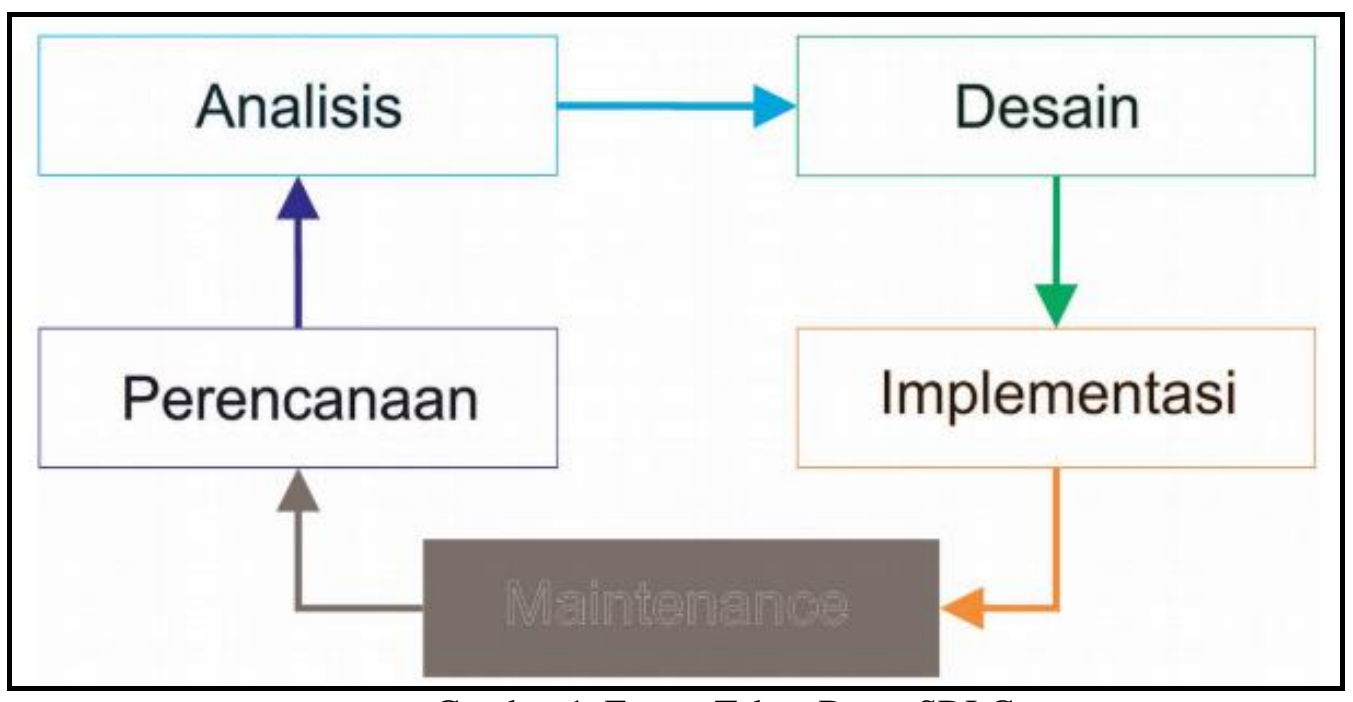

Gambar 1. Empat Tahap Dasar SDLC

a. Perencanaan

Tahapan ini menjelaskan bahwa sebelum menjalankan suatu proyek, ada baiknya untuk merencanakan analisa keuangannya terlebih dahulu. 
b. Analisis

Dengan analisa yang baik maka kondisi dan prasyarat suatu proyek dapat dilihat secara lebih mendalam.

c. Desain

Tahap ini akan merealisasikan rencana yang telah dianalisis. Namun realisasi disini bukanlah realisasi yang nyata layaknya sebuah produk. Realisasinya di sini lebih pada tahap desain sistem. Dengan dibuatnya desain ini maka kejelasan hasil tahapan analisis sebelumnya akan terjamin dalam bentuk dokumen. Dan akan lebih diarahkan pada penggunaan UML, dimana diharapkan tahapan-tahapan pembuatan program menggunakan website dapat dipermudah dengan memperjelas hasil perancangan berupa diagram UML.

d. Implementasi

Banyak kegiatan yang dapat dilaksanakan karena pada tahap inilah desain yang telah dibuat pada tahap sebelumnya akan terealisasi.

e. Maintenance

Tahap ini pada dasarnya akan muncul ketika produk atau sistem benar-benar telah dibuat. Salah satu indikator produk yang baik terlihat masih dalam tahap perawatan dibandingkan dengan produk yang belum menghasilkan.

\section{HASIL DAN PEMBAHASAN}

Dalam poin ini peneliti akan sedikti menjelaskan mengenai sistem yang dibuat dengan menggambarkan melalui use case diagram, class diagram dan rancangan sistem yang dibuat berbasis website.

\subsection{Use Case Diagram Sistem}

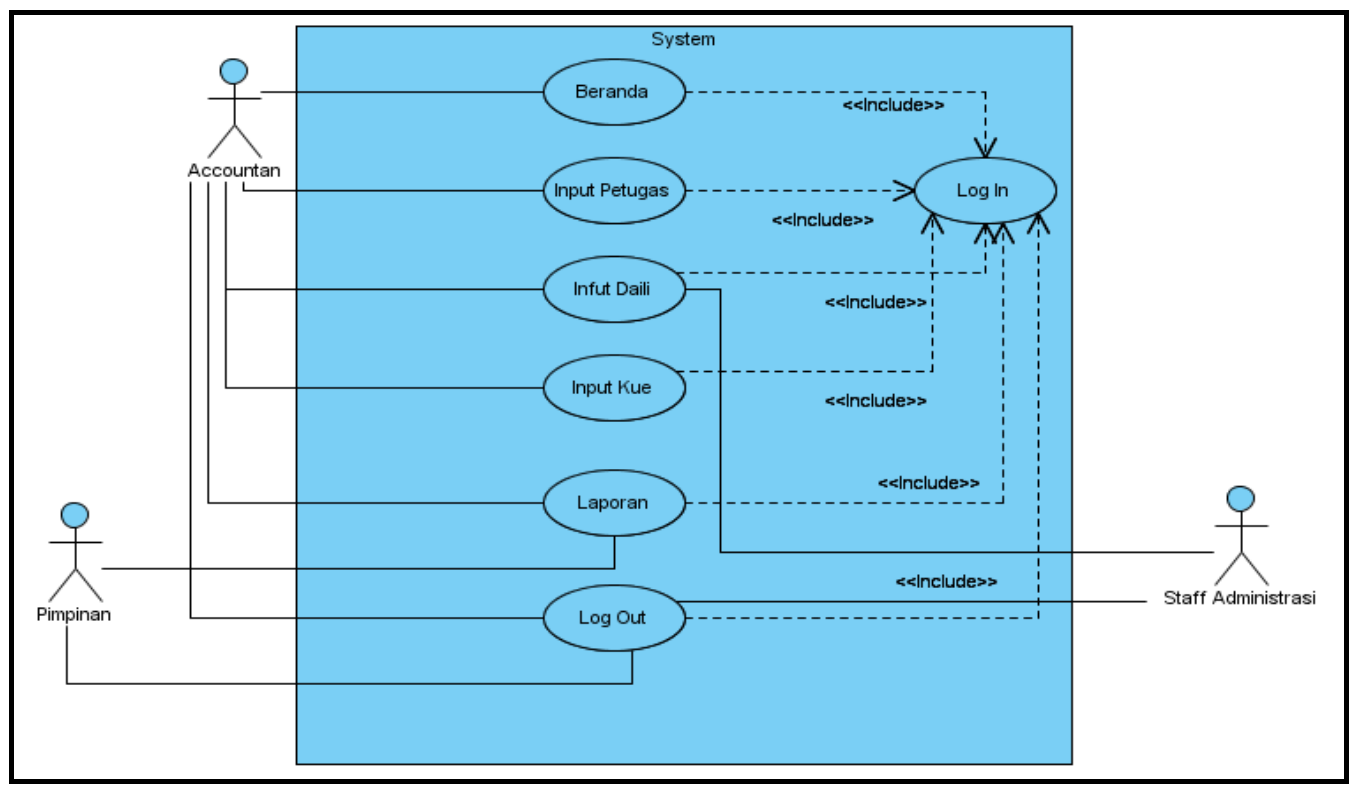

Gambar 2. Use Case Diagram Sistem

Penjelasan dari gambar 2 mengenai use case diagram sistem menerangkan bahwa terdapat : 1 sistem yang mencakup seluruh aktivitas yang sedang berlangsung; actor 
yang melakukan kegiatan ada 3 orang, yaitu: Akuntan, Pimpinan, dan Staf Tata Usaha; dan ada 7 use case yang biasanya dilakukan oleh para actor

\subsection{Class Diagram Sistem Laporan Penjualan Kue}

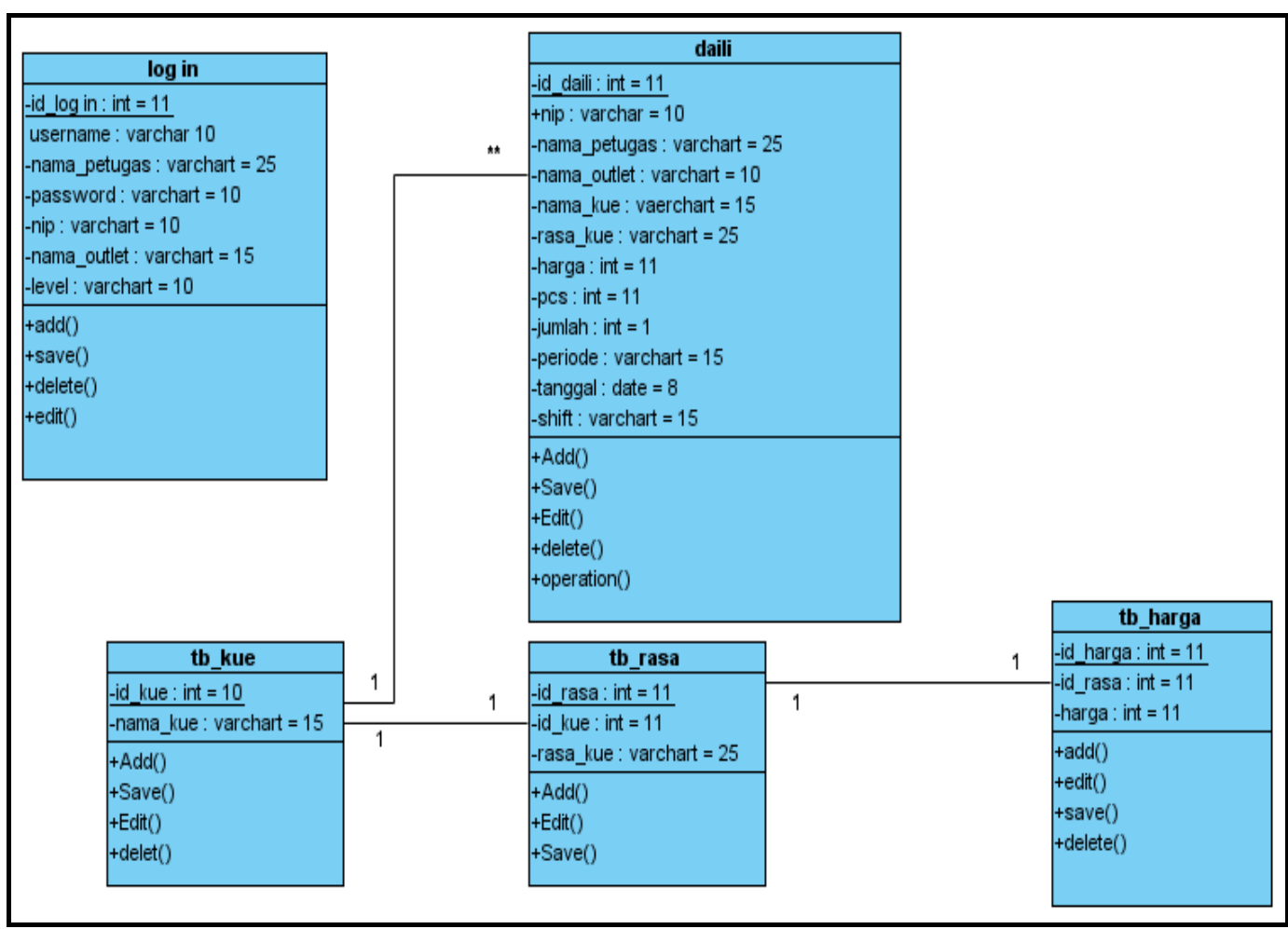

Gambar 3. Class Diagram Sistem Laporan Penjualan Heart Snack

Penjelasan dari gambar 3 mengenai class diagram sistemyang dibuat terdapat: 5class, himpunan dari objek-objek yang berbagi atribut serta operasi yang sama diantaranya login, daily, tb_kue, tb_rasa, tb_harga; dan ada 3 multiciply yang mengaitkan satu objek dengan objek lainnya yang memiliki nilai dengan keterangan one (1) to one (1) maupun one (1) to many (M).

\subsection{Desain Rancangan Program}

a. Rancangan Tampilan Web Beranda 


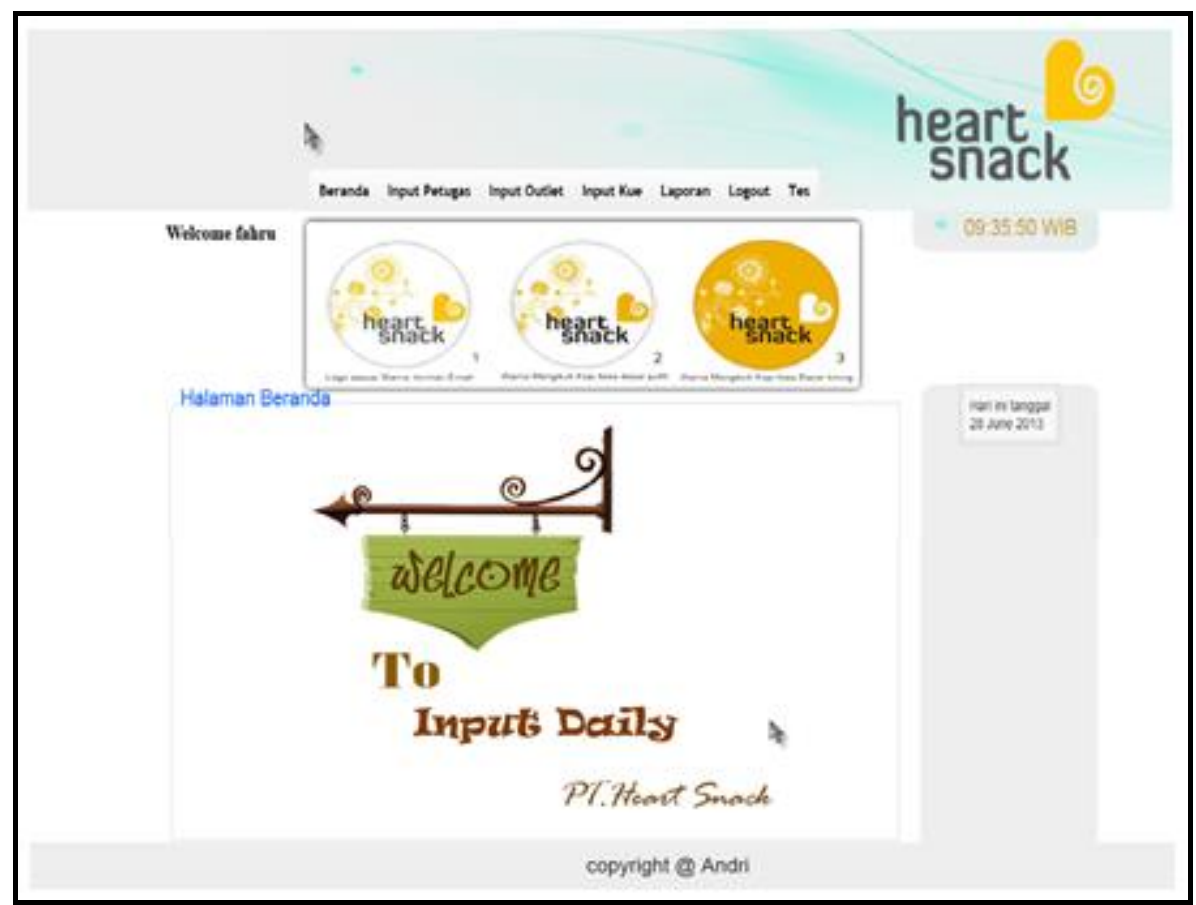

Gambar 4. Rancangan Tampilan Web Beranda

Gambar 4 tampilan awal program, menu di bagian atas merupakan menu umum yang berfungsi menampilkan Home, input staf, input outlet, input cake, laporan dan logout.

b. Tampilan Menu Input Petugas

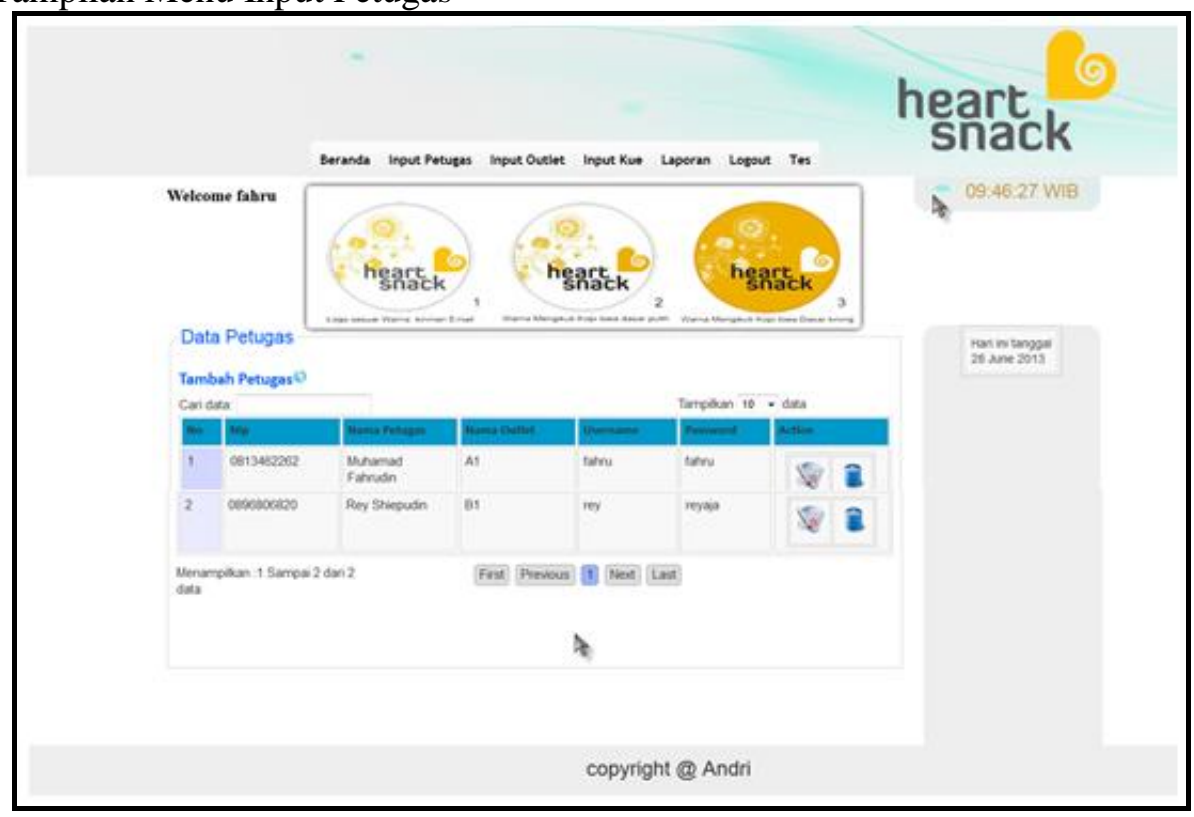

Gambar 5. Tampilan Menu Input Petugas

Gambar 5 merupakan halaman admin dalam menu input petugas yang berisi data petugas. 
c. Tampilan Menu Input Outlet

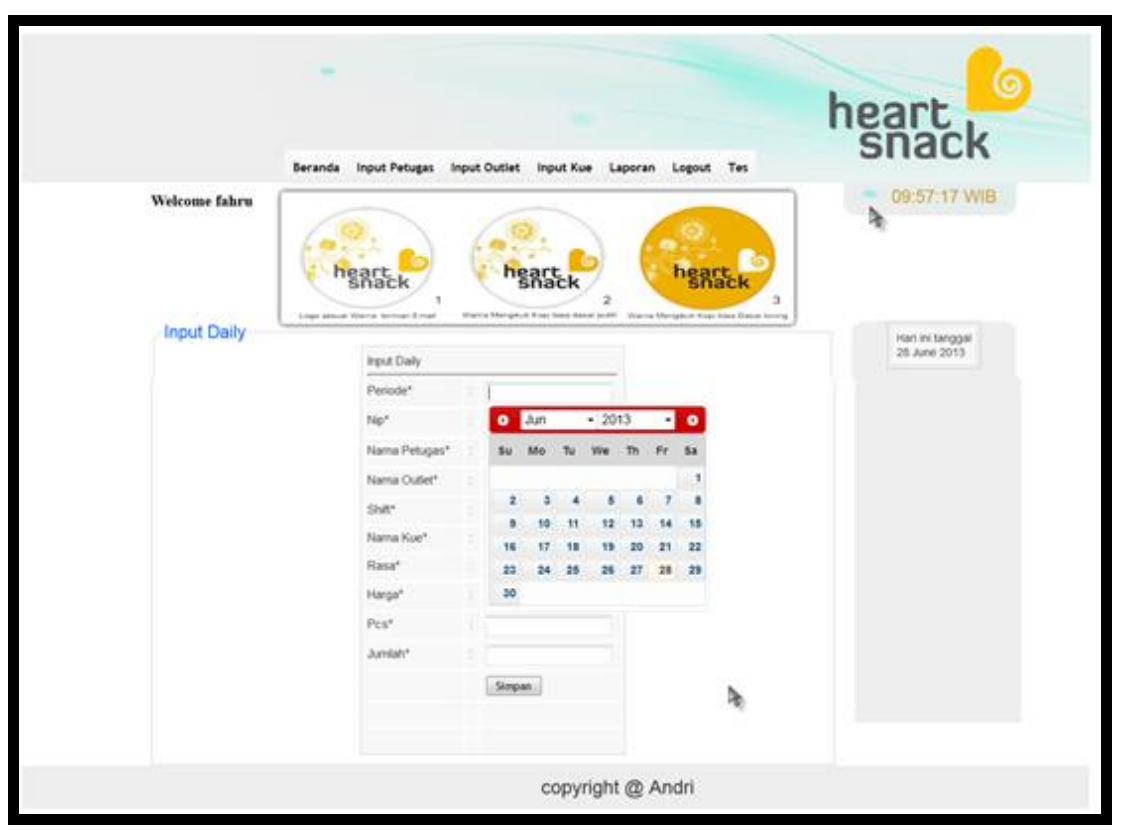

Gambar 6. Tampilan Menu Input Outlet

Gambar 6 merupakan halaman menu input outlet yang berisi form inputan harian.

d. Tampilan Menu Input Kue

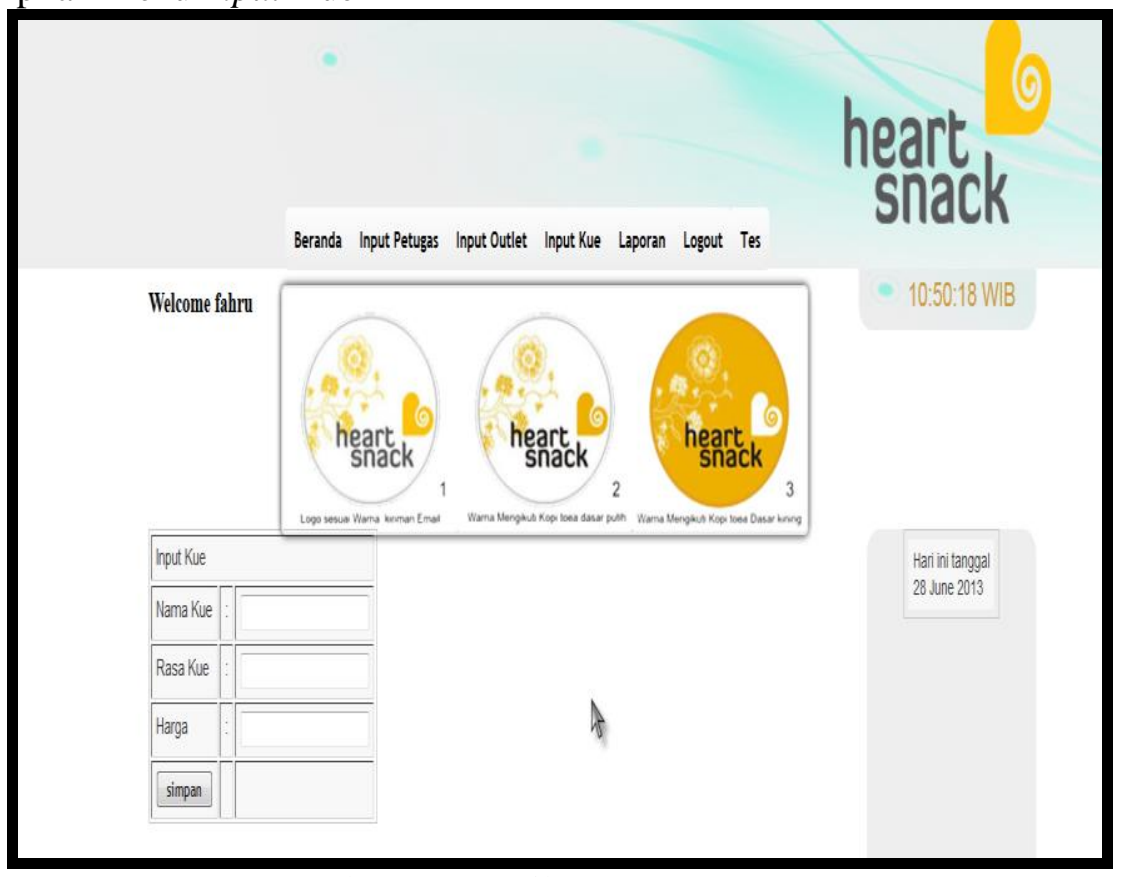

Gambar 7. Tampilan Menu Input Kue

Gambar 7 merupakan halaman input kue diantaranya, nama kue, rasa kue, harga kue, dan tombol simpan untuk menyimpan data input kue. 
e. Rancangan Tampilan Laporan Kue Per Outlet

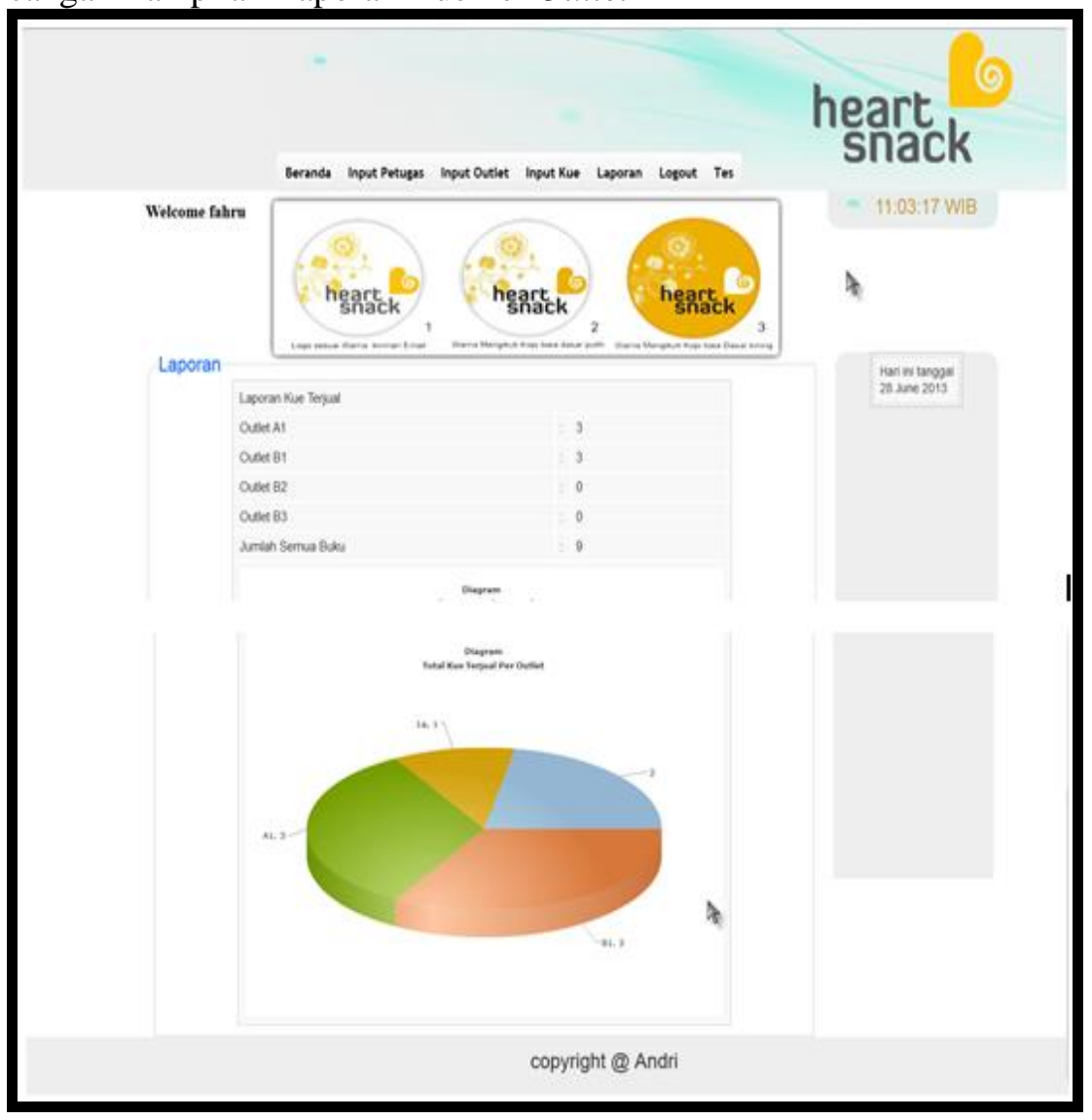

Gambar 8. Rancangan Tampilan Laporan Kue Per Outlet

Gambar 8 merupakan tampilan halaman menu laporan kue per outlet yang terjual.

f. Rancangan Tampilan Laporan Penghasilan Per Outlet

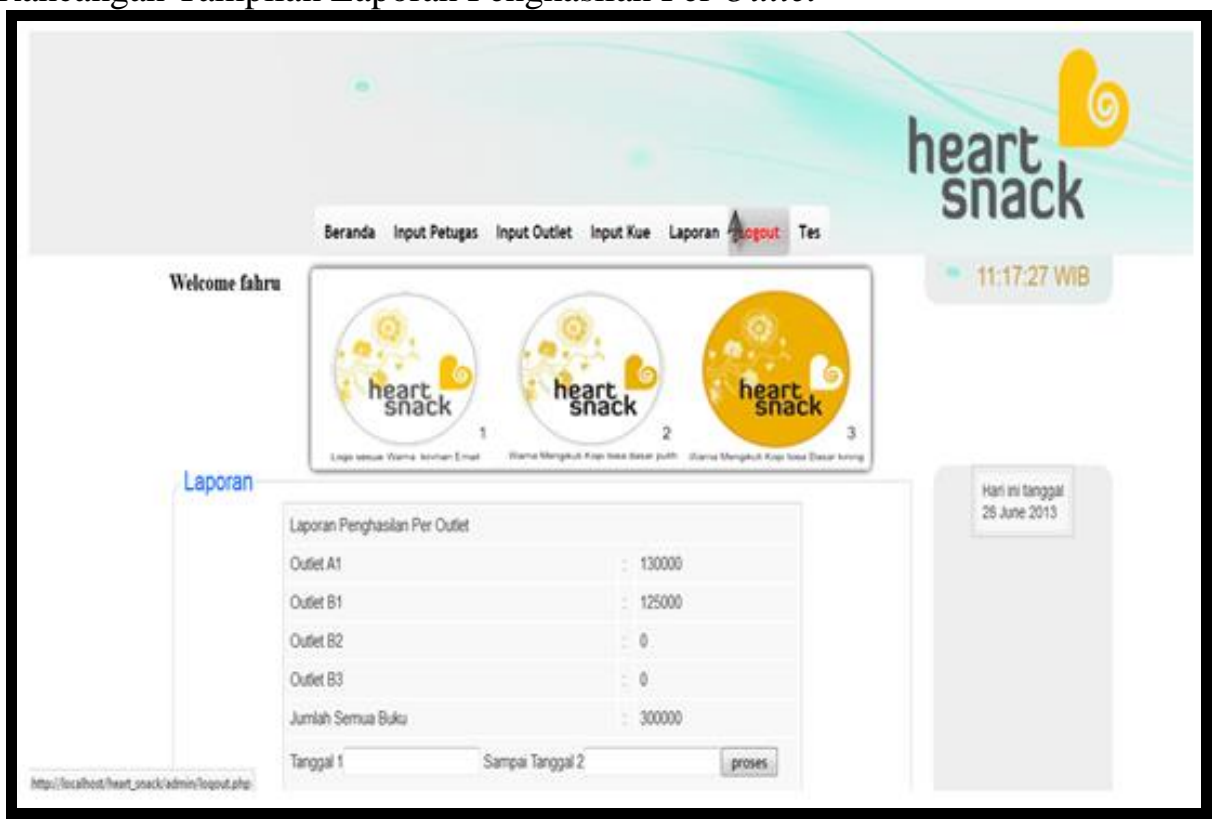

Gambar 9. Rancangan Tampilan Laporan Penghasilan Per Outlet 
Gambar 9 merupakan tampilan halaman menu laporan penghasilan penjualan kue per outlet yang terjual.

\section{KESIMPULAN}

Kesimpulan dari penelitian yang dibuat meliputi :

Dalam pengolahan laporan penjualan masih belum optimal dimana proses pembuatan laporan penjualan kue masih ditulis secara manual sehingga sering terjadi kesalahan dalam pembuatan laporan tersebut. Oleh karena itu, diperlukan sebuah sistem yang dapat membuat laporan penjualan kue dengan mudah sehingga tidak terjadi kesalahan dalam pembuatan laporan.

\section{SARAN}

Saran yang diperhatikan agar pengolahan data pada sistem dapat berjalan dengan baik yaitu:

Perlu memperhatikan dan evaluasi sistem secara berkala untuk perbaikan lebih lanjut sesuai dengan perubahan dan perkembangan di instansi atau perusahaan, dan dalam proses pemasukan data, pengolahan dan pelaporan data diperlukan aplikasi pendukung yang terkomputerisasi, seperti berbasis website maupun berbasis android.

\section{DAFTAR PUSTAKA}

[1] Rosalin, S., Susilowati., Natalia, D, C., \& Ambulani, N. 2020. Komunikasi Bisnis (Pendekatan Praktis). Malang: UB Press

[2] Prehanto, Dedy Rahman. 2020. Buku Ajar Konsep Sistem Informasi. Surabaya : Scopindo Media Pustaka

[3] Mahmud, W. 2018. Bisnis Online Untuk SMK/MAk Kelas XII. Jakarta : PT Gramedia Widiasarana Indonesia

[4] Kristiadi, Dedy Prasetya., \& Ferry. 2021. Metode Kuantitatif Pengambilan Keputusan Mengukur Kepuasan Pengguna Web Pada Perguruan Tinggi. Klaten : Lakeisha

[5] Wijoyo, Hadion., Ariyanto, Aris., Sudarsono, Agus., \& Wijayanti, Kiki Dwi. 2021. Sistem Informasi Manajemen. Sumatra Barat : ICM Publisher

[6] Ishak, R., Handini, W., \& Setiaji. 2018. Rancangan Bangun Sistem Informasi Penjualan Kue Dan Roti Berbasis Web Pada Yuki Bakery Jakarta. Jurnal Swabumi. 6(1), 27-34.

[7] Nurhayati, Y. 2017. Implementasi E-Commerce Dalam Meningkatkan Penjualan Kue Di Toko Kemuning. Jurnal Cloud Information. 3(2), 42-49.

[8] Sintawati, I, D. 2018. Pembuatan Sistem Informasi Penjualan Kue Berbasis Web Dengan Metode RAD (Rapid Application Development). Journal Of Information System, Applied, Management, Accounting And Research. 2(4), 1-6.

[9] Hendini, A. 2016. Permodelan UML Sistem Informasi Monitoring Penjualan Dan Stok Barang (Studi Kasus: Distro Zhezha Pontianak). Jurnal Khatulistiwa Informatika. 4(2), 107-115.

[10] Saputra, M, H, K., \& Aprilian, L, V. 2020. Belajar Cepat Metode SAW. Bandung : Kreatif Industri Nusantara.

[11] Susanto, E. 2019. Pemrograman Android Dengan Menggunakan Eclipse \& StarUML. Surabaya : Airlangga university Press. 